REVISIÓN DE LITERATURA

\title{
FACTORES QUE AFECTAN LA INCUBABILIDAD DE HUEVO FÉRTIL EN AVES DE CORRAL
}

Jimena Rodríguez-Moya ${ }^{1}$, Ana Isabel Cruz-Bermúdez ${ }^{1}$

\section{RESUMEN}

La avicultura es una de las áreas de la zootecnia que se encuentra más especializada en el sector agropecuario de Costa Rica. En la actualidad, los modelos de las granjas reproductoras, en producción de huevos fértiles, no utilizan la incubación natural, en cambio optaron por sistemas de incubación artificial que propician un medio ambiente muy similar al de la naturaleza, pero de manera más eficiente.

El éxito de la incubación artificial de los huevos inicia desde el manejo de la granja de reproductores, donde se debe tener control de la nutrición, manejo sanitario, reproducción, ganancias de peso, etc. Posteriormente el manejo del huevo fértil es fundamental, el traslado de la granja hacia la planta de incubación debe ser cuidadoso y seguir buenas prácticas para asegurar un adecuado porcentaje de incubabilidad, el almacenamiento e incubación de los huevos están basados en los fundamentos básicos cómo son: temperatura, humedad, ventilación y movimiento. Es por esta razón que es elemental investigar sobre los agentes que afectan la incubabilidad en aves, pero en específico con gallinas ponedoras y pollos de engorde, ya que son las explotaciones avícolas más comunes y de mayor impacto económico en el país.

Palabras clave: industria avícola, incubación, granja avícola, aves reproductoras, incubabilidad

\footnotetext{
${ }^{1}$ Fundecooperación para el Desarrollo Sostenible.

${ }^{2}$ Egresada de la Escuela de Zootecnia. Universidad de Costa Rica. San José, Costa Rica.

Autor para correspondencia: jrodriguez@fundecooperacion.org 


\section{ABSTRACT}

Factors affecting fertile eggs hatch ability in poultry. Poultry farming is one of the animal science areas that is most specialized in the agricultural sector of Costa Rica. At present, the models of the breeding farms, in production of fertile eggs, do not use the natural incubation, instead they chose artificial incubation systems that propitiate an environment very similar to the nature, but in a more efficient way.

The success of the artificial incubation of eggs starts from the management of the reproducers farm, where it must have control of nutrition, sanitary management, reproduction, weight gain, etc. Afterwards, the fertile egg management is fundamental, the transference from the farm to the hatchery must be done taking care and following good practices to ensure an adequate hatchability percentage; the storage and incubation of the eggs are based on the basic fundamentals such as: temperature, humidity, ventilation and movement. Because of all this, it is elementary to investigate the agents that affect hatchability in birds, but specifically with laying hens and broilers, since they are the most common poultry farms with the greatest economic impact in the country.

Keywords: industry, poultry, incubation, farm, reproducers

\section{INTRODUCCIÓN}

Los productos de origen animal de mayor consumo en Costa Rica son lácteos, huevos y carne de pollo, lo cual hace de la industria avícola una de las explotaciones más especializadas del sector agropecuario (Sáenz, 2001). La industria avícola costarricense posee la reputación de ser una de las más avanzadas de Centroamérica, en Costa Rica con una población de 4.3 millones de personas, el consumo per cápita de pollo es de $23.3 \mathrm{~kg}$ y 141 huevos de plato (Wright, 2010).

Hace unas décadas atrás, la avicultura en Costa Rica era una actividad de tipo rústico y artesanal, donde su objetivo era sólo abastecer de carne y huevos para el consumo 
familiar y lo demás venderse a la población. Dicha explotación avanza con el paso del tiempo y de la mano con la tecnología, se mejoran los métodos de producción, lo que hace de la carne y huevos, alimentos imprescindibles en la dieta de los costarricenses, aún para sectores del país con bajos recursos.

En la actualidad, la incubación natural fue eliminada de los modelos de explotación avícola comercial. Esto porque desde una perspectiva económico-productiva, una incubación natural es menos eficiente debido a que no permite trabajar con números altos de producción, pues el ave puede atender un número reducido de huevos y la disponibilidad de los mismos es menor (Bonilla y Díaz, 1987). Dada esta situación, se desarrolló la incubación artificial, la cual propicia un medio ambiente similar al de un ave que incuba sus huevos y se basa en el control de la temperatura, humedad, ventilación y movimiento.

La industria avícola en la última década se ha desarrollado vertiginosamente a nivel cuantitativo como cualitativo, constituyéndose así la incubación como una de las áreas determinantes con gran desarrollo y cuya finalidad es producir un pollito saludable y de excelente calidad (Herrera, 2011). Por ende, es fundamental investigar los agentes que afectan la incubabilidad en aves, ya que son de gran importancia para el desarrollo del embrión, y de presentarse fallas en el proceso, afectan de manera significativa la producción.

\section{PRINCIPALES FACTORES QUE AFECTAN LA INCUBABILIDAD}

Según Vaca (1999), la incubabilidad es el porcentaje de huevos fértiles, que al ser incubados llegan a producir pollitos. Esta característica productiva está muy regulada por la herencia y puede influenciarse por factores nutricionales y sanitarios en las hembras reproductoras, así como por condiciones desfavorables en el proceso de incubación en planta.

La palabra incubación deriva del latín incubare, que significa "acostarse sobre". Esto es lo que hacen casi la totalidad de las aves para incubar sus huevos, acostarse o echarse sobre ellos para lograr que lo embriones se desarrollen y se conviertan en polluelos (Vaca, 2003). La incubación, por tanto, es necesaria para la reproducción de las aves, y puede darse de forma natural o artificial.

En la actualidad, los avances en genética han logrado líneas de gallinas ponedoras y pollos de engorde con un potencial de incubabilidad alto. Sin embargo, de acuerdo con 
Sardá y Vidal (2005) son muchos los factores que afectan el proceso de incubación y es fundamental saber hacer un buen análisis de los datos disponibles para reconocer posibles problemas.

En un escenario comercial, la incubabilidad es la cantidad de pollitas y pollitos de primera calidad, sanos, con buena vitalidad, que son aptos para la crianza. Es un indicador que se calcula respecto a la cantidad de huevos colocados en la incubadora, expresado en porcentaje. La incubabilidad puede afectarse por distintas causas, que se presentan en resumen en el Cuadro 1.

Cuadro 1. Causas que afectan la incubabilidad de los huevos

\begin{tabular}{lc}
\hline \multicolumn{1}{c}{ Causas } & $\%$ \\
\hline Deficiencia de vitaminas y minerales & 1,0 \\
Huevos no fecundados & $1-4$ \\
Contaminación & 0,1 \\
Roturas y defectos de la cáscara & 1,0 \\
Conservación deficiente & 1,0 \\
No adaptación al régimen de incubación & $3-4$ \\
Problemas de metabolismo embrionario & 0,5 \\
Defectos internos del huevo & 1,0 \\
\hline
\end{tabular}

Fuente: Adaptado de Sardá y Vidal (2005)

\section{FACTORES PREVIOS A LA INCUBACIÓN QUE AFECTAN LA INCUBABILIDAD}

\section{Manejo del huevo fértil: de la granja a la planta}

Una buena incubación comienza desde la recolección de los huevos en las granjas y se debe hacer en un tiempo próximo a la postura para evitar contaminación de los mismos. La recolección de huevos fértiles debe hacerse con el debido cuidado y seguir con precaución las instrucciones de sanidad y bioseguridad de cada granja. Luego de la selección de los mejores huevos, basada en parámetros como frescura, ausencia de daños externos y adecuado peso (Figura 1); se procede a desinfectarlos y colocarlos en bandejas, procurando una uniformidad de tamaño de huevo (Vaca, 
1999). El lugar de almacenamiento debe ser fresco y ventilado y se recomienda almacenarlos con la punta hacia abajo.

De acuerdo con Hernando (1990), para evitar pérdida de fertilidad por este concepto, se recomienda hacer 4-5 recogidas de huevos diarias, repartidas entre la mañana y la tarde, también después de cada recogida es muy conveniente la fumigación de los huevos en caliente para rebajar la posible carga microbiana mediante la aplicación de formol y permanganato. La fumigación debe hacerse a una temperatura de $20-25^{\circ} \mathrm{C}$ y a una humedad relativa entre el 70 y el $80 \%$ durante unos minutos.

El manejo al que se someten los huevos es una de las principales causas de una mala incubabilidad, pero también de fácil diagnóstico. Siempre es importante considerar que se manejan embriones, por lo que se tienen que manipular con cuidado y a nivel de condiciones ambientales. Según afirma Herrera (2011), la manipulación brusca de los huevos durante su recolección, almacenamiento y transporte puede provocar fisuras en la cáscara, esto afecta de forma directa en la productividad, ya que todo huevo fisurado que se coloca en la incubadora no nace, por lo tanto, mantener un manejo cuidadoso del huevo es muy importante, y el cual debe hacerse desde el nido hasta la colocación en la incubadora.

Al momento de la puesta, el huevo sale a $42^{\circ} \mathrm{C}$, luego es recolectado con cuidado, llevado a la planta y seleccionado, durante este tiempo se adapta a la temperatura ambiental $24-25^{\circ} \mathrm{C}$. Al colocar los huevos en el cuarto frío, el crecimiento embrionario se detiene y se mantiene un estado de letargo desde 2 hasta un máximo de 15 días, siendo el tiempo óptimo 4 días (Herrera, 2011).

El almacenamiento de los huevos es un factor de gran relevancia para no perder potencial de nacimiento con los huevos fértiles. Según Juárez (2014), las condiciones ambientales de los cuartos fríos donde se almacenan deben ser entre 15 y $20^{\circ} \mathrm{C}$ con $75-80 \%$ de humedad relativa.

En el Cuadro 2, se ejemplifica la importancia del efecto que tiene la temperatura y el periodo de almacenamiento sobre la incubabilidad del huevo, de acuerdo a un estudio realizado por el Departamento de Medicina y Zootecnia de Aves de la UNAM en México (Juárez, 2014); donde a mayor periodo de almacenamiento, menor debe ser la temperatura del cuarto frío. 
Cuadro 2. Influencia del tiempo de almacenamiento del huevo fértil sobre la incubabilidad.

\begin{tabular}{ccc}
\hline & \multicolumn{2}{c}{ Porcentaje de Incubabilidad } \\
\hline $\begin{array}{c}\text { Temperatura } \\
\text { Almacenamiento }\end{array}$ & $\begin{array}{c}\text { Tiempo } \\
\text { Almacenamiento }\end{array}$ & $\begin{array}{c}\text { Tiempo } \\
\text { Almacenamiento }\end{array}$ \\
\hline 15 & $\mathbf{1 - 4}$ días & $\mathbf{5 - 1 0}$ días \\
20 & $73,4 \%$ & $76,2 \%$ \\
25 & $76,3 \%$ & $75,0 \%$ \\
& $74,9 \%$ & $72,6 \%$ \\
\hline
\end{tabular}

Adaptado de: Juárez, 2014.

Diferentes investigaciones documentan que en especies avícolas, un almacenaje mayor a una semana disminuye la incubabilidad, por lo que el almacenaje del huevo fértil debe ser menor a 7 días. De esa manera, se optimiza la calidad de los componentes del huevo, se mantiene estable el desarrollo embrionario, se favorece la sobrevivencia del embrión y lo más importante es que se mejora la incubabilidad y calidad del pollito eclosionado.

De acuerdo con lo anterior, Fasenko et al. (2001), comparó un almacenaje de embriones de pollo de engorde de 4 días (10,7\% mortalidad) versus 14 días (27,27\% mortalidad), además determinó que en este último grupo la mortalidad temprana y tardía se acentúo de manera significativa.

Juárez (2014) afirma que existe evidencia de que el metabolismo embrionario cambia debido al tiempo de almacenaje de los huevos. En un estudio efectuado por Fasenko et al. (2002), se observó que los embriones de huevos almacenados por 15 días producían una cantidad de $\mathrm{CO}_{2}$ a una tasa menor que la producida por los embriones provenientes de huevos almacenados sólo 4 días, esto indica que los embriones provenientes de un largo almacenaje no sólo son más lentos en su desarrollo, si no que su metabolismo se afecta debido al almacenaje previo a su incubación. 


\section{Peso del huevo}

El peso del huevo de gallina puede oscilar entre 50 y 65 gramos y puede ser influenciado por factores tales como: el tamaño de la hembra, el momento del ciclo de puesta, la subespecie y la alimentación. El peso del huevo determina de forma clara y positiva el peso del pollo al nacimiento, aspecto importante para la vitalidad del recién nacido. Por otra parte, el tamaño del huevo influye en la viabilidad de los pollitos, donde los huevos de gran tamaño producen pollos edematosos y de nacimiento tardío, debido a una falta de intercambio gaseoso y de vapor de agua. Por el contrario, los huevos muy pequeños producen pollos deshidratados, de pequeño tamaño y muy débil al nacimiento, esto por la gran pérdida de agua durante el proceso de incubación (Solano, 2009).

\section{Calidad de la cáscara}

Según Fernández y Arias (2000), el grosor de la cáscara varía entre 1,4 y 2,4 mm, con un valor medio entre 1,8 y $2,0 \mathrm{~mm}$, influyendo en la mayor o menor pérdida de agua durante el proceso de incubación.

Por lo tanto, se deben eliminar huevos con cáscaras delgadas, que presenten poros y/o deposiciones de calcio, ya que presentarán problemas durante la incubación. Además, se deben eliminar todos aquellos huevos con anormalidades y fisuras en la cáscara, ya que el riesgo de contaminación por microorganismos patógenos es muy elevado (Solano, 2009). Esta clasificación se evidencia con claridad en la Figura 1. 


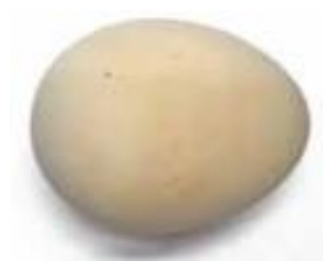

Pálido

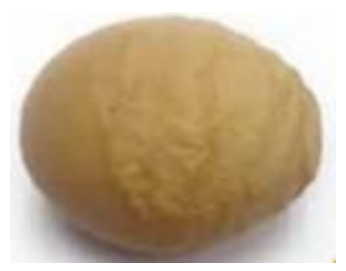

Corrugado

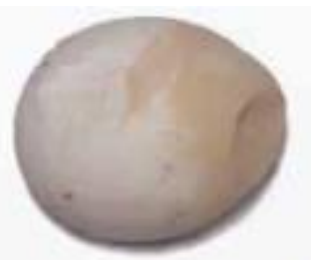

Suave o farfara

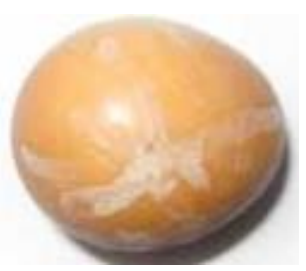

Sucio

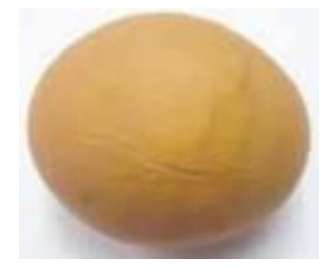

Arrugado

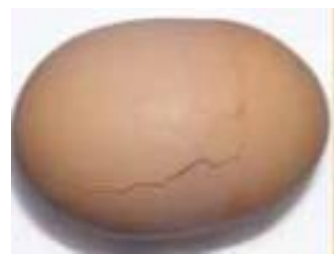

Quebrado

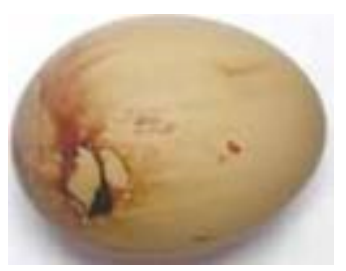

Manchas de sangre

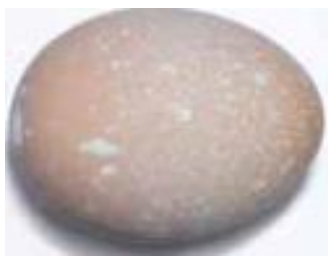

Depósitos de calcio

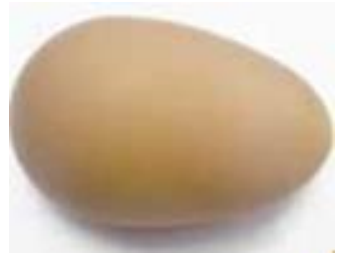

Deforme

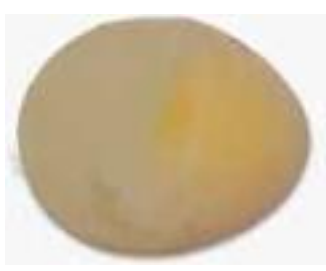

Sin Cáscara

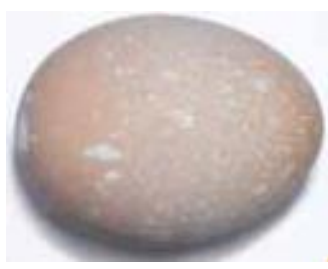

Áspero o rugoso

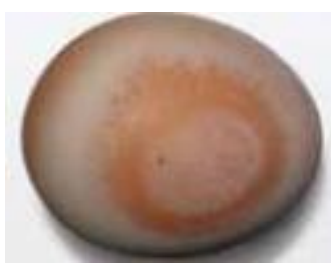

Línea blanca

Figura 1. Posibles defectos de huevos fértiles. Fuente: Alltech (2014)

\section{Estado sanitario de los reproductores}

La presencia de agentes infecciosos a lo largo del oviducto y en la cloaca puede provocar la contaminación de los huevos, y con esto, una baja tasa de incubabilidad, una elevada mortalidad embrionaria y un menor peso de los pollos al nacimiento. Por otra parte, cualquier proceso patológico que provoque alteraciones metabólicas importantes y una disminución en la absorción de los nutrientes de la dieta, puede ocasionar alteraciones en el desarrollo embrionario (Vidal, 2003). En este sentido, se debe vigilar la presencia de parásitos internos, ya que en ocasiones son los responsables de una menor disponibilidad de nutrientes por parte del organismo animal. Por ello, se recomienda la desparasitación regular de los reproductores.

Además Méndez (2013), asegura que la presencia de enfermedades en los reproductores repercute de manera severa en el porcentaje de incubabilidad (lo que nace) y de nacimientos útiles (lo que se logra vender), tales como la bronquitis infecciosa, Mycoplasmaspp, NewCastle, entre otros. 


\section{Edad de los reproductores}

En general, los machos reproductores alcanzan la madurez sexual posterior a las hembras quienes se espera que a la semana 22 ya estén poniendo huevos de calidad. El período de postura de una gallina reproductora liviana dura alrededor de 70 semanas, mientras las reproductoras pesadas ponen huevos viables durante 40 semanas (Gámez, 2011); la época en la cual se encuentre afectará la calidad del huevo y por tanto el porcentaje de incubabilidad (Vázquez et al., 2006).

Cuadro 3. Diferencias de la calidad del huevo según la edad de la gallina reproductora

\begin{tabular}{|c|c|c|c|}
\hline $\begin{array}{l}\text { Edad de la } \\
\text { reproductora }\end{array}$ & $\begin{array}{c}\text { Características del } \\
\text { huevo }\end{array}$ & Manejo del huevo & $\begin{array}{c}\% \text { Incubabilidad } \\
\text { promedio }\end{array}$ \\
\hline 22 - 35 semanas & $\begin{array}{l}\text {-Huevos pequeños } \\
\text {-Cascarón resistente } \\
\text {-Albúmina densa }\end{array}$ & $\begin{array}{c}\text {-Más tiempo almacenado } \\
\text {-Almacenado a mayor } \\
\text { temperatura } \\
\text {-Menor humedad en el } \\
\text { cuarto de almacenamiento }\end{array}$ & $82 \%$ \\
\hline 35 - 45 semanas & $\begin{array}{c}\text {-Tamaño óptimo de } \\
\text { huevo } \\
\text {-Buena resistencia } \\
\text { cascarón } \\
\text {-Albúmina adecuada }\end{array}$ & $\begin{array}{l}\text {-Almacenamiento normal } \\
\text { de } 4 \text { a } 8 \text { días con } 80 \% \text { de } \\
\text { humedad en el cuarto }\end{array}$ & $87 \%$ \\
\hline 45 - 65 semanas & $\begin{array}{l}\text {-Huevos grandes } \\
\text {-Cascarón delgado } \\
\text {-Albúmina acuosa }\end{array}$ & $\begin{array}{l}\text {-No más de } 3 \text { días } \\
\text { almacenamiento } \\
\text {-Bajar temperatura de } \\
\text { almacenamiento } \\
\text {-Aumentar humedad } 85 \%\end{array}$ & $77 \%$ \\
\hline
\end{tabular}

Adaptado de: Vázquez et al., 2006.

\section{Estrés de los reproductores}

Cualquier situación de estrés que sufran las aves durante la época de reproducción, va a ocasionar una disminución en la de fertilidad y en la tasa de puesta, por lo que se debe evitar. Cuando la reproducción se da en grandes grupos, la presencia de machos muy dominantes que luchan de manera constante es una causa de estrés hacia las hembras, por lo que deberían apartarse. Por otra parte, las gallinas son muy sensibles al estrés sónico, por lo que las granjas de reproducción deben situarse lejos de las carreteras principales. Es debido a esto la relevancia de mantener una relación de 
1:10 macho/hembra, lo cual también va a depender de circunstancias locales y las condiciones de la parvada, entre ellas la edad de las reproductoras (Aviagen, 2013).

Asimismo, la presencia de perros y de animales salvajes puede causar estrés en los animales. Además, una manipulación excesiva de los reproductores, durante la época de monta, puede ocasionar una situación de estrés crónico, lo que afecta de forma negativa a la reproducción (Solano, 2013).

\section{Nutrición de los reproductores}

El huevo debe contener todos los nutrientes que el embrión necesita cuando es puesto por la gallina. La alimentación de la hembra influye tanto en la calidad como en el tamaño del huevo y, en consecuencia, en la viabilidad y peso al nacimiento del pollito. Es muy importante mantener una dieta equilibrada durante toda la época de reproducción, para evitar carencias vitamínico-minerales (Solano, 2009).

El requerimiento de proteína de las gallinas reproductoras, no sobrepasa los 16 gramos diarios, no obstante, si este requerimiento no se alcanza, la postura se ve afectada. Se considera tardía a una reproductora cuando pone su primer huevo después de las 28 semanas de edad y esa tardanza puede deberse a deficiencias nutricionales. Sin embargo, en la práctica, los avicultores intentan a menudo reducir el periodo de cría con un adelanto de la edad del primer huevo a fin de mejorar el número de pollitos por gallina. En estas condiciones se hace necesario el considerar de nuevo la necesidad en proteínas en comparación con animales que presentan diferentes precocidades sexuales y alimentadas con balanceados ricos en proteínas (Larbier, 1987).

La deficiencia de vitamina B12 (cobalamina) provoca cabeza entre piernas, pico roto, dedos torcidos y poco desarrollo muscular; mientras que la deficiencia de riboflavina (vitamina B2) causará un pulmón adelgazado, por lo que, según Bonilla y Díaz (1987), causa una elevada muerte embrionaria y los pollitos que logran nacer, morirán en los primeros días de vida. Por otro lado, la deficiencia de biotina y folacina en la dieta de la gallina reproductora, trae problemas en el desarrollo del pollito como: micromelia (acortamiento de huesos largos), huesos de las alas, patas y cabeza se presentan cortos y torcidos (Bonilla y Díaz, 1987).

Además, es de relevancia cuidar la composición corporal de las aves, un incremento en el peso de las reproductoras repercute en la monta, y por lo tanto en la postura de las hembras. Así lo indica Callejo (2012), el sobrepeso debe evitarse porque las aves 
que llegan a la madurez con un exceso de grasa, consiguen peores rendimientos que los que la alcanzan con el peso adecuado. Esta merma de la efectividad productiva se traduce en varios puntos: menor tamaño del huevo, menor número de huevos incubables, mayor riesgo de muerte por prolapso del oviducto.

\section{Bioseguridad de la granja}

En las granjas de reproductores, el programa de bioseguridad se convierte en una herramienta fundamental para garantizar el éxito del proceso. Todas las granjas deben contar con áreas limpias y sucias.

Los huevos sucios y de piso no deben de incubarse. Los huevos naturalmente limpios mantienen un mayor potencial de nacimiento que los huevos sucios o contaminados, sin importar los procedimientos de desinfección que se utilicen posteriormente (lañez, 1998).

Las bacterias y los hongos que pueden afectar a los huevos fértiles se encuentran en todas las partes del ambiente de los galpones, en el suelo, en las heces, y hasta en las partículas de polvo en el aire. La manera más común de que los huevos fértiles se contaminen es al ser puestos sobre una cama sucia de los nidos, en el piso o en las rejillas (Wineland y Christopher, 1998). Por lo que es sumamente importante contar con programas de bioseguridad en la granja y así disminuir las cargas bacterianas, que según Calnek (2000), pueden penetrar a través del cascarón durante la incubación e infectar los pollitos recién nacidos, además los hongos se puede localizar con facilidad en las incubadoras, nacedoras y cuartos de recepción.

De acuerdo con Argueta (2004), los contaminantes bacterianos que causan problemas en el huevo fértil, son principalmente las enterobacterias. Estas son bacilos gran negativos, aerobios y anaerobios facultativos. Son negativos a oxidasa, positivos a catalasa (hay algunas excepciones), no esporuladores, fermentativos (a menudo con producción de gas) y en general móviles.

Los huevos contaminados que no tienen un desarrollo embrionario en la incubadora pueden afectar también al desarrollo de otros huevos sanos. Si un huevo contaminado llega a explotar o agrietarse en la incubadora o en la nacedora, puede esparcir las bacterias a otros huevos o a los pollitos recién nacidos. De hecho, un huevo contaminado puede afectar a una planta de incubación entera (Wineland y Christopher, 1998). 
A continuación, algunas estrategias para minimizar la contaminación del huevo (Argueta, 2004):

- Recolectar frecuente de los huevos para minimizar el tiempo de exposición a un ambiente contaminado.

- Mantener la limpieza de la galera, incluyendo la cama de los nidales ya sean estas de almohadillas de plástico, de viruta o de paja.

- Introducir los huevos recolectados al cuarto frío de almacenamiento de huevos tan pronto como sea posible; las temperaturas frías y adecuadas del cuarto frío demorarán el crecimiento de las bacterias sobre la superficie de la cáscara.

- Impedir que la humedad se acumule sobre la cáscara. La humedad provee el nutriente necesario para el crecimiento microbiano y puede ser también una ayuda para el movimiento de microbios sobre la superficie de la cáscara.

- Uso adecuado de los programas autorizados para la fumigación o desinfección de huevos.

- Minimizar el número de huevos rotos o con grietas. Los contenidos de los huevos pueden proveer los nutrientes necesarios para que las bacterias se multipliquen y se diseminen.

- Evitar la limpieza de los huevos con lijas abrasivas ya que pueden afectar la estructura de la cáscara.

- Hacer un gran esfuerzo para minimizar la contaminación según avanza la edad de los reproductores, ya que Wineland y Christopher (1998) afirman que la cáscara se vuelve más delgada con la edad y está más expuesta a la infección bacteriológica.

\section{FACTORES QUE AFECTAN LA INCUBABILIDAD EN LA PLANTA DE INCUBACIÓN.}

El desarrollo embrionario no debe considerarse como algo aislado de las condiciones del medio que rodea a los huevos durante la incubación. Existe una determinada interrelación entre el medio del huevo y el medio externo que lo rodea, y como en todo sistema, existen agentes adversos que se deben tomar en cuenta para explicar ciertos índices de incubabilidad altos o bajos. Los cambios que tienen lugar en el huevo durante la incubación se presentan ordenados y regidos por leyes naturales. Estos cambios se producen, con normalidad, solamente bajo niveles determinados de 
temperatura, humedad, contenido químico del aire, posición del huevo, así como la limpieza de las máquinas (Vaca, 1999; Solano, 2009). Cualquier desajuste en alguno de los factores anteriores, puede provocar grandes diferencias en la cantidad y calidad de los pollitos que se obtengan.

Para poder identificar posibles factores que afectan la incubabilidad, es necesario conocer el proceso de desarrollo del embrión, con el objetivo de poder ubicar posibles causas de mortalidad embrionaria según el período en el que se presente o problemas de fertilidad en las parvadas. Es fundamental aclarar que un huevo no fertilizado no puede producir un polluelo, y la fertilidad de la parvada depende del manejo de machos y hembras en la granja de reproductores, y no se puede mejorar mediante el manejo del huevo, su almacenamiento o las condiciones de incubación.

Por su parte, la mortalidad embrionaria temprana sí puede ser afectada por los factores anteriores. Por lo tanto, es importante entonces poder reconocer la diferencia entre infertilidad y mortalidad embrionaria temprana, ya que las acciones que se requieren para corregir la mala fertilidad no son las mismas que para corregir mortalidad temprana excesiva (Mouldin, 2001).

Los resultados de la incubación vienen determinados en un inicio por los padres, su genética y su capacidad de puesta, así como por las condiciones en que se lleve a cabo la incubación propiamente dicha (Scholtyssek, 1970). Algunos de los factores que afectan la incubabilidad en la planta de incubación se ahondarán a continuación.

\section{Equipo de incubación}

Según Díaz y Bonilla (2003) existen incubadoras comerciales horizontales y verticales; que se diferencian por la forma y dimensiones, pero en ambos casos cuentan con ambientes cerrados, calentados y aislados, que permiten un ambiente apto para el desarrollo embrionario. Las incubadoras horizontales se encuentran en sectores o seccionales, con ventilación natural y humedad sin regulación automática. Las bandejas se encuentran al mismo nivel, con capacidad de 50 a 500 huevos. Por otro lado, las incubadoras verticales trabajan con altos volúmenes de huevos y son en forma de armario, llamadas también de tipo gabinete, con sistema de calefacción, ventilación y volteos eléctricos, donde se disponen las bandejas unas sobre otras (López, 1985).

Todas las máquinas incubadoras tienen una fuente de humedad que pueden controlar varios niveles de humedad relativa. El aire fresco suplementa un poco de humedad de esta manera reduce la carga en el sistema de humidificación interna, el aire entrante a 
las máquinas es pre-humidificado para igualar lo más cercano posible la humedad relativa interna. La temperatura del aire debe ser de $24-27^{\circ} \mathrm{C}\left(76-80^{\circ} \mathrm{F}\right)$.

De acuerdo con Espinoza et al. (2010), para los fabricantes de incubadoras el reto actual consiste en diseñar máquinas que permitan un óptimo desarrollo embrionario para cada huevo y cualquier fase de desarrollo. Existen muchos tipos de incubadoras y muchas marcas las cuales tienen 2 diferentes sistemas para lograr el balance dentro de la incubadora. Entre los tipos de máquinas se tiene la multi-etapa y la de una sola etapa.

La multietapa contiene colocaciones de huevos de diferentes lotes que permite incubar huevos de fechas diferentes al mismo tiempo, en cambio la de una sola etapa, solo posee espacio para la colocación de un lote de huevos y para una sola fecha de nacimiento (Espinoza et al., 2010).

Según afirma Master Chick (2005), las incubadoras multi-etapa requieren una constante cantidad de aire. Esta debe ser ajustada para que los niveles de dióxido de carbono dentro de la máquina no excedan $0,4 \%$, donde la mayoría realizan este ajuste entre $0,2 \%-0,3 \%$.

En una máquina multi-etapa, la temperatura debe permanecer constante. La temperatura óptima para incubabilidad y calidad del pollito dependerá del tipo de incubadora. Temperaturas más altas o más bajas de las que recomiendan los fabricantes conllevarán a desarrollos más rápidos o más lentos y consecuentemente a la reducción en incubabilidad.

Mientras que en máquinas incubadoras de una etapa, la temperatura puede ser alterada para el crecimiento del embrión y para la producción de calor, comenzando con una temperatura más alta y reduciéndola en diferentes etapas hasta la transferencia. El balance incorrecto al cargar máquinas de multi-etapa puede crear variaciones significantes de temperatura. Máquinas parcialmente llenas no podrán alcanzar temperaturas correctas y prolongan el tiempo de incubación, mientras que sobrecargar puede crear problemas de sobrecalentamiento. Ambas condiciones afectarán adversamente la incubabilidad y la calidad del pollito. 


\section{Temperatura}

La temperatura es el factor más importante para que tenga lugar el desarrollo del embrión. Tanto un exceso como un nivel inferior al óptimo provocan un aumento porcentual del número de pollitos nacidos con malformaciones y una reducción de los porcentajes de eclosión, con las consecuencias lógicas de merma en la producción de pollitos viables (Díaz y Bonilla, 2003). En general, en la gallina se considera óptima una temperatura de entre $37,5^{\circ} \mathrm{C}$ y $37,7^{\circ} \mathrm{C}$ en el interior de las incubadoras y entre $36,1^{\circ} \mathrm{C}$ y $37,2^{\circ} \mathrm{C}$ en el de las nacedoras (Juárez, 2014). Cuando se establece la temperatura con la que se quiere trabajar, es necesario mantenerla en ese punto preciso.

La temperatura de las nacedoras también es de suma importancia ya que es un poco más baja que la de la incubadora con el fin de reducir el riesgo de sobrecalentamiento. También es de relevancia regular la temperatura y que esta sea uniforme dentro del nacedero, para evitar la disminución en la humedad y que el pollito no tenga la capacidad de salir al picotear ya que se queda pegado en las membranas secas de la cáscara (Tullet, 2009).

Las temperaturas más altas de lo normal, afectan más que las más bajas, ya que provocan la muerte del embrión, así como fuerte deshidratación, nacimientos prematuros y alta mortalidad de los pollitos al nacer y durante los primeros días de vida (López, 1985). Por otro lado, una temperatura de incubación insuficiente (baja), prolonga la duración de la misma, así como pollitos inmaduros y de aspecto débil (Vaca, 1999).

\section{Humedad}

Durante la incubación, parte del agua del huevo se pierde por evaporación y parte por ser absorbida por el embrión, así que es necesario restituir esa humedad. Con una adecuada humedad se obtendrá buena conformación ósea y buen tamaño de los pollitos (López, 1985). La humedad relativa interna en incubadoras varía entre 55\% y $65 \%$ y en nacedoras entre $65 \%$ y $75 \%$. Varía según el tamaño del huevo. Así, cuanto mayor sea el peso o el tamaño, menor será el porcentaje de humedad.

Según Vaca (1999), la humedad relativa es uno de los aspectos más descuidados de la planta de incubación, sin embargo tiene enorme influencia sobre el desarrollo del embrión y el intercambio gaseoso. Si la humedad es muy alta, el embrión no se 
oxigena lo suficiente, lo que produce asfixia o intoxicación al no poder eliminar el dióxido de carbono, dando como resultado retardo en el nacimiento y pollitos grandes con el abdomen abultado y blando al tacto. Además, pollitos pegados al cascarón se derivan de esta condición. En contraste, si se presenta una humedad baja, el huevo perderá mucha agua y se deshidratará, dando como resultado pollitos pequeños, duros, con un aspecto reseco y áspero en el plumaje (Quintana, 1988).

\section{Ventilación}

El embrión respira, por lo tanto es necesario eliminar el $\mathrm{CO}_{2}$ que se acumula en la cámara de incubación, debido a su toxicidad. Con una correcta aireación de todos los huevos se logran una temperatura y humedad uniformes (Scholttyssek, 1970).

El aire debe contener entre $21 \%$ y $22 \%$ de oxígeno, y no más de $0,5 \%$ de dióxido de carbono. Para asegurar un aporte adecuado de oxígeno contenido en el aire de la cámara incubadora, esta se debe ubicar en un lugar con abundante aireación o con ventilación especial auto controlada, por medio de ventiladores exteriores. Un aumento en el porcentaje de dióxido de carbono provoca anormalidades, lentitud de desarrollo y debilidad del embrión (López, 1985).

\section{Posición y volteo de los huevos}

Los huevos para incubación deben estar colocados con el polo o punta más ancha arriba. A pesar de que este detalle es tan importante, es fácil encontrar $2 \%$ a $3 \%$ de los huevos colocados con la parte ancha hacia abajo; se sabe que un alto porcentaje de estos huevos mal colocados no eclosionan (Vaca, 1999). Esto se debe a que la cámara de aire se encuentra en el polo ancho y ahí es donde se dirige la cabeza del embrión en desarrollo. Un huevo mal colocado provoca problemas al embrión y por ende reduce sus posibilidades de nacer (Yoho et al., 2008).

De acuerdo con Díaz y Bonilla (2003), para un buen desarrollo del embrión, es indispensable la rotación del huevo, ya que de lo contrario, el embrión tendería a adherirse a las paredes de la cáscara, lo que impediría ubicarse de manera adecuada para el nacimiento. A medida que el embrión se desarrolla y la producción de calor aumenta, un volteo regular ayudará al flujo de aire y por tanto al enfriamiento (CobbVantress, 2010). Esta operación es esencial durante la primera semana de incubación, 
la cual se efectúa varias veces al día, y pierde importancia hasta ser innecesaria en la nacedora. Esto porque a partir del sexto día de incubación, el embrión empieza a efectuar movimientos voluntarios o contracciones que impiden que se pegue a las membranas internas de la cáscara (Quintana, 1988).

Un insuficiente volteo de los huevos puede provocar que los pollitos nazcan en posiciones anormales, deformes o con el plumón corto y áspero. Si se voltean los huevos en una sola dirección, se provocará ruptura de vasos sanguíneos y de yemas, lo que ocasiona una alta mortalidad embrionaria (Quintana, 1988).

\section{Bioseguridade Higiene de la planta incubadora}

Un buen diseño es esencial para operar una planta de incubación a un costo razonable. Las plantas forman parte de la cadena productiva, y su diseño debe incorporar, por lo tanto, todas las normas sanitarias y de bioseguridad para asegurar un buen funcionamiento de la misma. Las condiciones que se implementen para mantener el crecimiento embrionario en las incubadoras son también ideales para el crecimiento de bacterias y hongos. La superficies externas de los huevos deben estar libres de contaminación al igual que las superficies de los cuartos o salas; las partes de los equipos y las maquinas incubadoras deben ser diseñadas para facilitar la limpieza regular y simples y la esterilización efectiva (López-Oropeza, 2007).

De acuerdo con Herrera (2011), las áreas limpias deben estar separadas para evitar contaminación por plumón que puede esparcirse por todos lados a través de corrientes de aire, por lo que el sistema de ventilación debe garantizar un movimiento de aire de las áreas limpias a las sucias y nunca en sentido contrario, o sea en la misma dirección de los huevos, de las incubadoras a las nacedoras. Estos sistemas también necesitan una limpieza periódica, por lo tanto deben ser de fácil acceso para dicho propósito.

Las paredes y pisos deben ser durables y los desagües de fácil drenaje, las paredes lisas que permitan una limpieza efectiva, el piso debe estar inclinado hacia el desagüe en cada piso de la planta incubadora. Todo desagüe necesita de una rejilla para evitar que se tape con cascarón o desechos, en especial en las áreas de nacedoras y donde se saca el pollito. Todo el sistema de drenaje debe ser diseñado para el manejo de grandes cantidades de agua y material sólido (Vaca, 2003). 
Para evitar problemas por contaminación del huevo en la incubadora, es necesario limpiar todas las superficies por donde se trasladan los huevos y pollitos recién nacidos (pisos, puertas, pasillos, paneles de ventilación, etc.). Otras posibles fuentes de contaminación pueden incluir el aire, los trabajadores y visitantes, roedores, insectos, huevos contaminados, plumón y el equipo (Cobb-Vantress, 2010).

Cuando las incubadoras están vacías, al haberse transferido el huevo a las nacedoras, se procede a la limpieza. Antes de la desinfección de la incubadora, se debe remover todo material orgánico, con un lavado de agua y detergente. Después de que se efectúa la limpieza de su interior, se debe aplicar un desinfectante adecuado, que no posea efecto nocivo para la próxima carga de huevos, ni para el material de que están hechas las máquinas. Las recomendaciones anteriores se aplican de igual manera para las nacedoras (Vaca, 1999). Esta actividad deberá incrementarse de manera significativa cuando se presenten problemas de enfermedades.

En el Cuadro 4, se presenta un resumen de los problemas y posibles causas y medidas correctivas para algunos de los inconvenientes observados cuando ocurre una baja en la incubabilidad. 
Cuadro 4. Principales problemas y causas que disminuyen la incubabilidad en aves.

\begin{tabular}{|c|c|}
\hline Problema & Causas \\
\hline Infertilidad Real & $\begin{array}{l}\text {-Machos inmaduros, Machos no montan } \\
\text {-Reproductores viejos, Parásitos }\end{array}$ \\
\hline $\begin{array}{l}\text { Fértil sin desarrollo (huevos claros } \\
\qquad \text { al ovoscopio) }\end{array}$ & $\begin{array}{l}\text { - Temperaturas altas o bajas } \\
\text {-Choques térmicos (Temperatura disminuida o incrementada } \\
\text { rápidamente) } \\
\text {-Fumigación inadecuada }\end{array}$ \\
\hline $\begin{array}{l}\text { Huevos claros al ovoscopio, se } \\
\text { puede ver un círculo de sangre o el } \\
\text { embrión pequeño }\end{array}$ & $\begin{array}{l}\text {-Huevos almacenados por mucho tiempo o bajo condiciones de } \\
\text { temperatura inadecuadas } \\
\text {-Enfermedades, Infertilidad } \\
\text {-Deficiencias nutricionales } \\
\text {-Consanguinidad en reproductores }\end{array}$ \\
\hline $\begin{array}{l}\text { Muchos embriones muertos } \\
\text { (7 días antes del nacimiento) }\end{array}$ & $\begin{array}{l}\text {-Temperatura inapropiada } \\
\text {-Inadecuado volteo de huevos } \\
\text {-Enfermedades, Consanguinidad } \\
\text {-Huevos contaminados }\end{array}$ \\
\hline $\begin{array}{l}\text { Embriones mueren antes de } \\
\text { comenzar a romper la cáscara }\end{array}$ & $\begin{array}{l}\text {-Temperaturas bajas durante incubación } \\
\text {-Huevos infectados } \\
\text {-Deficiencias nutricionales } \\
\text {-Ciertos factores genéticos letales }\end{array}$ \\
\hline $\begin{array}{c}\text { No picoteo. Embrión } \\
\text { completamente desarrollado }\end{array}$ & $\begin{array}{l}\text {-Volteo inadecuado, Humedad alta en incubadora } \\
\text {-Temperatura baja/alta en incubadora/nacedora } \\
\text {-Herencia }\end{array}$ \\
\hline $\begin{array}{l}\text { Picoteo. Embrión desarrollado, } \\
\text { muerto en el cascarón }\end{array}$ & $\begin{array}{l}\text {-Humedad o temperatura baja durante tiempo prolongado } \\
\text {-Temperatura alta durante nacimiento } \\
\text {-Mala ventilación, Volteo inadecuado }\end{array}$ \\
\hline Nacimiento temprano & $\begin{array}{l}\text {-Huevos pequeños } \\
\text {-Diferencias entre razas } \\
\text {-Temperatura alta en incubadora } \\
\text {-Humedad muybaja en incubadora }\end{array}$ \\
\hline Nacimiento tardío & $\begin{array}{l}\text {-Huevos grandes, Reproductores viejos } \\
\text {-Huevos almacenados por mucho tiempo } \\
\text {-Temperatura muybaja, Humedad muyalta }\end{array}$ \\
\hline $\begin{array}{l}\text { Pollitos adheridos a la cáscara, } \\
\text { secos }\end{array}$ & $\begin{array}{l}\text {-Humedad muybaja en almacenamiento/incubadoras/nacedoras } \\
\text {-Volteo inadecuado } \\
\text {-Huevos quebrados o de cascarón de mala calidad }\end{array}$ \\
\hline Ombligos abiertos & $\begin{array}{l}\text {-Fluctuaciones grandes de temperatura } \\
\text {-Humedad muyalta en nacedora } \\
\text {-Almacenamiento de huevos }\end{array}$ \\
\hline Pollitos anormales & $\begin{array}{l}\text {-Pico torcido: hereditario o infección viral } \\
\text {-Pérdida de ojos: altas temperaturas o manejo } \\
\text {-Cuello anormal: nutrición } \\
\text {-Dedos torcidos: temperatura ynutrición }\end{array}$ \\
\hline
\end{tabular}

Fuente: Adaptado de Wilson y Suarez (2004) y Cobb-Vantress (2010). 


\section{CONSIDERACIONES FINALES}

La mortalidad embrionaria es una variable a tomar en cuenta cuando existen problemas de baja incubabilidad, con la finalidad de realizar ajustes y tener éxito en los nacimientos (mayor cantidad de pollitos vivos). Es importante llevar a cabo estudios y registros de todas las áreas que integran una planta incubadora, de tal forma que se puedan analizar de forma oportuna las causas de muerte embrionaria con el fin de discernir si es un problema de operación o de fertilidad del huevo en sí.

El éxito del proceso de incubación artificial en huevos depende del manejo de la granja de reproductores, donde se debe tener control de la nutrición de las reproductoras, de enfermedades, de la actividad de apareamiento, de que no haya daño en los huevos, del peso corporal correcto de hembras y machos, de la higiene del huevo y el almacenamiento del mismo.

Es fundamental verificar las condiciones de incubación (temperatura, humedad, volteos, posición), así como la bioseguridad en la misma y el manejo del pollito para así disminuir los inconvenientes en la planta y obtener un pollito de buena calidad. El análisis de los residuos de la incubación, aunque no permite dar un diagnóstico definitivo, es una herramienta útil para determinar las áreas a ser examinadas.

Es de suma importancia que el personal encargado del manejo de huevos, de la incubadora y de la granja de reproductores trabaje como un equipo, para así facilitar la detección de algún problema y tomar las medidas correctivas necesarias.

\section{LITERATURA CITADA}

Alltech European Bioscience Centre. 2014. 20 Common Egg Shell Quality Problems. Poster. Poultry Advantage.

Argueta, F.M.G. 2004. Comparación de dos productos (formaldehído y paraformaldehído) usados en la desinfección de cama de nidos en granja de aves reproductoras y el efecto de cada uno sobre el porcentaje de incubabilidad. Tesis. Universidad De San Carlos De Guatemala Facultad De Medicina Veterinaria y Zootecnia. Escuela De Medicina Veterinaria, Guatemala.

Bonilla, O., Díaz, O. 1987. Elementos básicos para el manejo de animales de granja: Aves. Euned. San José, Costa Rica. p. 46-57. 
Calnek, B.W. 2000. Enfermedades de las aves. Ed. J.A. Cedillo J. Trad. A Lemus Gamboa, AF Martínez Haro. 2 ed. México, D.F, El Manual Moderno. p. 1110.

Cobb Vantress, 2010. Guía De Manejo De La Incubadora. Consultado el 15 de mayo del 2013. Disponible en: http://www.cobb-vantress.com/docs/defaultsource/guides/cobb- hatchery-management-guide---spanish.pdf?sfvrsn=0

Cobb Vantress, 2013. Guía de Manejo de la Incubadora. Disponible en: http://67.43.0.82/docs/default-source/guides/cobb-hatcherymanagement-guide--spanish.pdf?sfvrsn=2

Fasenko, G.M., F.E. Robinson, A.l. Whelan, K.M. Kremeniuk, y J.A. Walker. 2001. Prestorage incubation of long-term stored broiler breeder eggs. 1. Effects on hatchability. Journal of Poultry Science 80:1406-1411

Fasenko, G.M., F.E. Robinson, J.C. Segura, J.J.R. Feddes, y C.A. Oullette. 2002. Long term hatching egg storage alters the metabolism of broiler embryos. Journal of Poultry Science 80(1):62

Fernández, M.S., y J.L. Arias. 2000. La cáscara del huevo: Un modelo de biomineralización. Monografías de medicina veterinaria 20 (2).

Gámez, J. 2011. Evaluation of Yellow Follicles Production at the end of the Laying Period in a Commercial Broiler Breeder Farm. Revista científica 21(2).

Hernando, A.A. 1990. Factores que influyen sobre el huevo incubable. Selecciones avícolas, 32(10):295-298.

Herrera, A., y R. Diocelina. 2011. Influencia del tiempo de almacenamiento previo a la incubación sobre el desarrollo embrionario, incubabilidad y calidad del pollito finquero. Tesis de Grado previa a la obtención del Título de Médico Veterinario Zootecnista. Universidad Nacional de Loja, Loja, Ecuador.

lañez, E. 1998. Acción de los agentes químicos sobre las bacterias (en línea). Consultado el 04 de febrero del 2004. Disponible en http://www.ugr.es/_eianez/Microbiologia/ 19_Micro.htm

Juárez, M.A. 2014. Aspectos Críticos del Manejo y Almacenamiento del Huevo Fértil. Departamento de Medicina y Zootecnia de Aves, Facultad de Medicina Veterinaria y Zootecnia de la Universidad Autónoma de México, México.

Larbier, M. 1987. Necesidades nutricionales y técnicas de alimentación de las gallinas reproductoras. Universidad Autónoma de Barcelona. España. Consultado el 24 de Junio de 2013. Disponible en: http://ddd.uab.cat/pub/selavi/selavi_a1988m5v30n5/selavi_a1988m5v30n5p133 .pdf

López, M. 1985. Explotación comercial de aves. Albatros .República de Argentina. p. 354-369. 
López-Oropeza, M.Y. 2007. Experiencia en el manejo técnico de una planta de incubación. Planta Incubadora de Sofía, Prov. Andrés lbáñez Santa Cruz. (No. CIDAB-T-SF487-L61e). Universidad Autónoma Gabriel René Moreno. Facultad de Medicina Veterinaria y Zootecnia. Santa Cruz, Bolivia.

Master Chick, 2005. Estructura y modelos de incubadoras Chick Master. Disponible en: http://www.chickmaster.com/s_cm_product_upgrades.html

Mouldin, J. 2001. Guía de análisis de huevos no eclosionados para plantas de incubación. Revista Avicultura Profesional.19(10):18-23.

Quintana, J.1988. Avitecnia. Trillas, México. p. 215-222.

Sáenz, M. 2001. Encuesta Nacional de Consumo de Alimentos. Encuesta a hogares y de propósitos múltiples Ministerio de Salud. Costa Rica.

Sardá, R., y A. Vidal. 2001. Anatomía del Desarrollo Embrionario. La Habana, Cuba. Consultado el 19 de junio del 2013. Disponible en: http://albeitar.portalveterinaria.com/noticia/3498/ARTICULOS-AVESARCHIVO/Patologia-de-la-incubacion.html.

Scholtyssek, S.1970. Manual de avicultura moderna. Acribia, España. p.276-287.

Solano, C. 2009. Cuenca Rural. Consultado el 24 de Junio de 2013. Disponible en: http://www.cuencarural.com/granja/avicultura/62782manejo-de-huevosfertiles-para-incubar-a-nivel-de-granja-de-reproductoras/ 70

Tullet, S. 2009. Cómo investigar las prácticas de incubación. Ross Tech. Estados Unidos. Consultado el 17 de junio del 2013. Disponible en: http://avicol.co/descargas2/RossTechlnvpracticas.pdf

Vaca, L. 1999. Producción avícola. EUNED. San José, Costa Rica. p. 93-110.

Vaca, L. 2003. Producción avícola. EUNED. San José, Costa Rica. p. 102-109.

Vázquez, J., O. Prado, L. García, y M. Juárez. 2006. Edad de la reproductora sobre la incubabilidad y tiempo. Avances en Tecnología Agropecuaria. 10(1):21-28.

Vidal, A. 2003.Enfermedades infectocontagiosas de los reproductores. Patología de la incubación. La Habana, Cuba. p.6.

Wineland, M., y C. Christopher. 1998. Contaminación de los huevos fértiles. Trad. R del Pino. Universidad del Estado de Carolina del Norte, Estados Unidos.Disponible en http://www.geocities.com/raydelpino_2000/avicultura.html

Wright, C. 2010. Situación avícola de Costa Rica. Costa Rica. Consultado el 19 de Junio de 2013. Disponible en: http://www.wattagnet.com/La industria av\%C3\%ADcola costarricense.html

Yoho D., J. Moyle, A. Swaffar, y R. Bramwell. 2008. Effect of incubating poor quality broiler breeder hatching eggs on overall hatchability and hatch of fertile. Poultry Science. 87(1):148 